\title{
Gitelman Syndrome: an uncommon cause of hypokalaemia
}

\author{
Kumara KCR ${ }^{1}$, Nanayakkara PGCJ' ${ }^{1}$, Dayanath BKTP ${ }^{1}$, Weerarathna TP $^{2}$ \\ ${ }^{I}$ Teaching Hospital Karapitiya, Galle, Sri Lanka \\ ${ }^{2}$ Department of Medicine, Faculty of Medicine, University of Ruhuna, Galle, Sri Lanka
}

Correspondence: Dr.K.C.R. Kumara (chkottage@yahoo.com)

\section{Introduction}

Gitelman Syndrome (GS), first described by Gitelman et al in 1966 is an inherited autosomal recessive disorder (1). It is an uncommon disease. Clinical symptoms include fatigue, muscle cramps and weakness, carpopedal spasms and rarely generalized muscle paralysis and cardiac arrest $(2,3,4)$. Biochemical and metabolic characteristics of this syndrome include hypokalaemia, hypomagnesemia, hypocalciuria, metabolic alkalosis with normal blood pressure (5). Electrolyte disturbances are due to mutations in the thiazide sensitive $\mathrm{Na}-\mathrm{Cl}$ co-transporter (NCCT) in the distal convoluted tubule (3) Therefore, in an individual presenting with above symptoms along with biochemical and metabolic abnormalities, GS should be taken into consideration. This is a case of GS with classical symptoms and biochemical abnormalities which responded to treatment.

\section{Case Report}

A 36-year-old female presented with numbness in all four limbs and muscle cramps in both hands for one day duration. In the history, there was no vomiting, diarrhoea, laxative abuse or hypertension. Five years ago, she had a similar episode which was not investigated. Her brother is currently under investigation for similar symptoms.

On physical examination she had lean body habitus with a BMI of $19.8 \mathrm{~kg} / \mathrm{m}^{2}$. Her blood pressure was 100/80 mmHg and Chvostek's sign was negative. Examination of other major systems was unremarkable.

Investigations revealed normal basic haematological parameters and hypokalaemia, hypomagnesaemia, hypocalciuria with normal serum creatinine and blood urea (Table 1). Arterial blood gas analysis showed compensated metabolic alkalosis. Her thyroid and liver functions were normal. Renal ultrasonography showed no nephrocalcinosis. After evaluating her clinical and laboratory data the diagnosis of GS was made.

Table 1: Pre treatment haematological and biochemical parameters

\begin{tabular}{|c|c|}
\hline Parameters & $\begin{array}{l}\text { Patient } \\
\text { (normal) value }\end{array}$ \\
\hline Serum sodium $(\mathrm{mmol} / \mathrm{L})$ & $136 \quad(135-148)$ \\
\hline $\begin{array}{l}\text { Serum potassium } \\
(\mathrm{mmol} / \mathrm{L})\end{array}$ & $2.1 \quad(3.5-5.3)$ \\
\hline Serum chloride $(\mathrm{mmol} / \mathrm{L})$ & $94 \quad(95-110)$ \\
\hline Serum phosphorus (mg/dl) & $3.44 \quad(2.50-4.90)$ \\
\hline Serum magnesium (mg/dl) & $1.50(1.70-2.70)$ \\
\hline $\begin{array}{l}24 \mathrm{hrs} \text { urine calcium } \\
(\mathrm{mg} / 24 \mathrm{hrs})\end{array}$ & $97.60(100-300)$ \\
\hline $\begin{array}{l}24 \mathrm{hrs} \text { urine potassium } \\
(\mathrm{mmol} / 24 \mathrm{hrs})\end{array}$ & $31.70(<15)$ \\
\hline $\begin{array}{l}24 \mathrm{hrs} \text { urine sodium } \\
(\mathrm{mmol} / 24 \mathrm{hrs})\end{array}$ & $239.10(70-210)$ \\
\hline \multicolumn{2}{|l|}{ Blood gas analysis } \\
\hline $\mathrm{pH}$ & $7.527(7.35-7.45)$ \\
\hline $\mathrm{HCO}_{3}^{-}(\mathrm{mmol} / \mathrm{l})$ & $28.7 \quad(22-26)$ \\
\hline $\mathrm{PCO}_{2} \quad(\mathrm{mmHg})$ & $(35-46)$ \\
\hline $\mathrm{PO}_{2} \quad(\mathrm{mmHg})$ & $90 \quad(75-100)$ \\
\hline UFR & Normal \\
\hline Serum creatinine (umol/l) & $70 \quad(60-120)$ \\
\hline Blood urea $(\mathrm{mg} / \mathrm{dl})$ & $17 \quad(15-45)$ \\
\hline $\mathrm{FBC}$ & Normal \\
\hline Serum calcium (mg/dl) & $8.0 \quad(8.1-10.4)$ \\
\hline FBS & $89 \mathrm{mg} / \mathrm{dl}$ \\
\hline ESR & $251^{\text {st }}$ hour \\
\hline
\end{tabular}


She was started on oral potassium supplements and spiranolactone. After two days of therapy, her symptoms were markedly improved. Repeat biochemistry showed normal serum potassium and magnesium.

\section{Discussion}

Hypokalaemia can occur due to four main mechanisms. These include inadequate potassium intake, shift of potassium iron from extracellular to intracellular fluid compartment, non renal losses (i.e. sweating, vomiting and diarrhoea) and renal losses (3). At the beginning of the evaluation of a patient with hypokalaemia, pseudo hypokalaemia due to the extreme increase in the number of leukocytes should be eliminated (3). Leukocyte number was in the normal range in this patient. Vomiting and diarrhoea were not detected.

Shift of potassium from extra to intra-cellular compartment are known to occur in hypokalaemic periodic paralysis, thyrotoxicosis, and during treatment with insulin, salbutamol, theophylline and vitamin B12 $(3,5)$. In this case there was no history of use of such medications. The probable underling mechanism for hypokalaemia is therefore, increased renal loss. This was confirmed by finding of high urinary potassium level. Since this patient was normotensive and had metabolic alkalosis on arterial blood gas analysis, the differential diagnosis could be limited to two conditions namely GS and Bartter's syndrome(BS).

BS manifests during infancy or early childhood and in contrast to GS, shows increased or normal urinary calcium excretion (3). In this disorder, molecular defects are known to occur in the ascending limb of loop of Henle.

In GS, patients present during late childhood or adult age and the urinary calcium excretion is low (4). Biochemical findings of hypokalaemia, hypomagnesaemia, hypocalciuria and metabolic alkalosis in GS are known to occur due to genetic defect affecting the NCCT. This gene is located on chromosome 16 and a variety of mutations cause defects of $\mathrm{Na}-\mathrm{Cl}$ co-transporter function resulting in defective resorption of $\mathrm{Na}-\mathrm{Cl}$ at the distal convoluted tubule (4). Eventually, resorption of $\mathrm{Na}-\mathrm{Cl}$ reduces, so that $\mathrm{Na}-\mathrm{Cl}$ concentration increases in the collecting tubule. Elevated sodium level in this lumen leads to mild plasma volume contraction. Reduction of vascular volume activates renin-angiotensin-aldosterone system. In the cortical collecting tubules, elevated aldosterone level increases reabsorption of sodium and secretion of both potassium and hydrogen ions. Finally, hypokalaemia and metabolic alkalosis occur. At the same time the loss of thiazide sensitive cotransporter function can inhibit reabsorption of $\mathrm{Mg}$ via the apical $\mathrm{Na} / \mathrm{Mg}$ exchanger in the distal convoluted tubule leading to increase $\mathrm{Mg}$ excretion with resultant hypomagnesaemia $(3,4)$.

Considering the age of the patient and observed biochemical finding of hypokalaemia, hypomagnesaemia, hypocalciuria, metabolic alkalosis with normal blood pressure, the most likely diagnosis of this patient is GS. We could not confirm diagnosis with chromosomal testing due to non availability of such testing.

In the conclusion, GS should be considered in the differential diagnosis of an adult with hypokalaemia with normal blood pressure. Early recognition of this syndrome might prevent possible serious complications such as paralyses and cardiac arrest.

\section{References}

1. Gitelman HJ, Graham JB, Welt LG. A new familial disorder characterized by hypokalaemia and hypomagnesaemia. Trans Assoc Am Physicians, 1966; 79: 221-35.

2. Ng HY, Lin SH, Hsu CY, Tsai YZ, and Chen HC, Lee CT. Hypokalemic paralysis due to Gitelman syndrome: A family study. Neurology, 2006; 67: 1080-2.

3. Harrison's Principles of Internal Medicine. $17^{\text {th }}$ Edition, Vol 1: 280-284, Vol 2: 1800-1803.

4. Knoers NV, Levtchenko EN. Gitelman's syndrome. Orphanet Journal of Rare Diseases, 2008; 3: 22.

5. Kumar P, Clark M. Clinical Medicine, ${ }^{\text {th }}$ Edition, 704-6. 